\title{
Antioxidant Activity and Total Phenol Anthocyanin and Flavonoid Content Analysis of Rasberry
}

\author{
N.Srinivas Goud and Rohit Kumar Sinha
}

Renatus Wellness Pvt. Ltd. Hyderabad, Telangana, INDIA

\begin{abstract}
This study aim to investigate phytochemical and antioxidant activity of Rubus idaeus L fruit. The total phenolics, flavonoids and anthocyanins were evaluated. The antioxidant activities were investigated using three antioxidant assays 2,2diphenyl-1-picrylhydrazyl (DPPH), Ferric Reducing (FRAP) and 2,2'-azinobis(3-ethylbenzothiazoline-6sulfonic acid) (ABTS). The rasberry fruit contain of total phenolics $(37.19 \pm 0.39 \mathrm{mg} \mathrm{GAE} / \mathrm{g})$, flavonoids $(5.32 \pm 0.13 \mathrm{mg} \mathrm{RU} / \mathrm{g})$ and total anthocyanin content (32.21 $\pm 0.35 \mathrm{mg} \mathrm{c}-3-\mathrm{gE} / \mathrm{g})$ were recorded. The antioxidant activity in $\mathrm{DPPH}$ assay $\mathrm{IC}_{50}$ value $39.00 \pm 1.32 \mu \mathrm{g} / \mathrm{ml}$, ABTS assay $(0.85 \pm 0.02 \mathrm{mg}$ AEAC/g) and FRAP assay $52.03 \pm 4.65 \mathrm{mM} \mathrm{Fe} 2+/ \mathrm{g}$ were evaluated. These results presenting perspectives usage of R.idaeus fresh fruits was considerable levels of phytochemicals and antioxidant activity.
\end{abstract}

Keywords Phytochemical, Antioxidant, Rubus idaeus, 2,2-diphenyl-1-picrylhydrazyl, phenolics.1.

\section{Introduction}

The Rubus idaeus L.( raspberry) is a exclusive berry with a rich history. Consuming a healthy and diet loaded in vegetables and fruits is related with a compact risk of some lifestyle and noncommunicable age related diseases such as cancer, type2 diabetesmellitus (T2DM), cardiovascular disease (CVD) and Alzheimer disease. Red raspberries supply to the relating to diet value. It is food sources of dietary fiber $6.5 \mathrm{~g} / 100 \mathrm{~g}$ and calorie $12.5 \mathrm{~g} / 100$ kcal. It also have magnesium, vitamin $\mathrm{C}$, potassium, vitamin $\mathrm{K}$, calcium, and iron (USDA. Scientific report 2015).

Raspberry polyphenols principally consist of hydrolysable tannins and anthocyanins. Particularly, raspberries are a abundant source of cyanidin glycosides as well as unique from other berries due to high ellagitannin content resulting in the discharge of free ellagic acid during hydrolysis (Rao, A.V et al., 2010). Ellagitannins were showed extensively add to the antioxidant activity of raspberries.
Ellagitannins were responsible for $58 \%$ of antioxidant ability of raspberry fruits (Borges, G. et al., 2010). In addition, ellagitannins are exacting interest for nutritional and pharmacological induatries because of compounds may act as effective chemopreventive agents (Landele, J.M 2011).

In additionally minerals and vitamins, the phytochemicals in raspberry has been related to such kind of benefits reduced risk of cardiovascular disease, weight management, reduced blood pressure and cholesterol, improved cognitive brain function, stroke and slowed agerelated eyesight degeneration (Zafra-Stone et al., 2007). Bioactive compounds can work as proteins, antioxidants, lipids, stopping or limiting damage to cellular DNA caused by reactive oxygen species. A strong relation between eating of antioxidant loaded foods and cancers and decreased risk of cardiovascular disease (Heinonen, I et al., 1998).

Rasberries extracts have been established to make use of antimicrobial, anti-inflammatory, antioxidant, anticancer, anti-Alzheimer activities and anthelminthic (. Jim'enez-Arellanes et al., 2012; C. S. Bowen-Forbes et al., 2010; H. Jung et al., 1886) . The bioactivities of rasberry are mostly due to the presence of phytochemicals. Previous studied have shown that black raspberries presented the highest amount of anthocyanin, total polyphenols and flavonoid while compared to Korean raspberries and blackberries. It is also reported that antiinflammatory activities and high antioxidant activity by rasberry due to high concentration of polyphenols and anthocyanin (Heinonen, I et al., 1998).

\section{Materials and Methods}

\subsection{Materials}

Rasberry fruits were procured by local medicinal herbs supplier. Fruits were air dried and made it powder and stored in laboratory condition. 


\subsection{Reagents and Solvents}

All reagents and solvents 2,2-diphenyl-1picrylhydrazyl (DPPH free radical) and diphenylboryloxyethylenamine (DPhBOA) were procured from Sigma-Aldrich.

\subsection{Extract Preparation}

Rasberry powder $20 \mathrm{~g}$ was extracted with $100 \mathrm{ml}$ methanol at room temperature for $24 \mathrm{hrs}$ under constant shaking. The extract were filtered and dried in a rotary vacuum evaporator to remove methanol. After evaporation, the residue was suspended in methanol for further analysis.

\subsection{Total Anthocyanin Content.}

Total anthocyanin content was determined by with a spectrophotometric $\mathrm{pH}$ differential method with some modification (M. M. Giusti et al., 2001). The reaction mixture follow as, $0.5 \mathrm{~mL}$ extract was added $3.5 \mathrm{~mL}$ of potassium chloride buffer $(0.025 \mathrm{M}, \mathrm{pH}$ 1.0). The mixture was mixed and kept to stand for 15 minutes. The absorbance were calculated at 515 and $700 \mathrm{~nm}$. distilled water used as blank. Results were presented as mg cyanidin-3-glucoside equivalents (c$3-\mathrm{gE}) / \mathrm{g}$ of dried sample.

The total anthocyanins content was calculated by following formula:

Total anthocyanin content (mg/g of dried sample)

$\frac{A \times \mathrm{Mw} \times \mathrm{DF} \times 10}{(\varepsilon \times C)}$

where $A$ is absorbance $=(A 515-A 700), \mathrm{pH} 1.0-$ (A 515-A 700)

$\mathrm{pH} 4.5, \mathrm{Mw}$ is molecular weight for cyanidin-3glucoside $=449.2$, DF is a dilution factor of the samples, $\varepsilon=$ the molar absorptivity of cyanidin-3glucoside $=26,900, C=$ the concentration of the buffer in $\mathrm{mg} / \mathrm{mL}$.

\subsection{Total phenolic content}

The Total Phenol Content was investigated using Folin-Ciocalteu method by Wootton-Beard (2011) with some modifications. $0.5 \mathrm{~mL}$ of extract mixed with $(10 \%) 2.5 \mathrm{~mL}$ Folin-Ciocalteu reagent and 2.5 $\mathrm{mL} \mathrm{NaHCO} 3(7.5 \%)$. The reaction mixture was incubated at $45{ }^{\circ} \mathrm{C}$ for $15 \mathrm{~min}$. Blank was prepared in the same way without adding of extract. The absorbance of were measured on the spectrophotometer at $765 \mathrm{~nm}$. Results were presented as mg gallic acid equivalents of dried sample.

\subsection{Total flavonoid content}

The total flavonoids content was determined by aluminum chloride (Brighente IMC et al., 2007). Briefly, $1 \mathrm{~mL}$ of the extract was mixed with (2\%)1 $\mathrm{mL}$ of $\mathrm{AlCl} 3$. The reaction mixture was incubated for 1 hour at room temperature. The absorbance was observed at $415 \mathrm{~nm}$. Total flavonoid content were expressed as mg of RU g-1.

\subsection{DPPH free radical scavenging assay}

DPPH free radical scavenging activity of rasberry extract was determined using DPPH method (Takao $\mathrm{T}$ et al., 1994). $1 \mathrm{~mL}$ of DPPH solution ((2 mg mL$1), 1 \mathrm{~mL}$ of different concentrations of the extract or the standard solution was added independently. The reaction mixtures were incubated at $37{ }^{\circ} \mathrm{C}$ for 30 min. The absorbance were measured at $517 \mathrm{~nm}$ using methanol as blank. The DPPH scavenging activity (\%) of extract and standard AA was determined using the following equation:

\%inhibition $=[($ Ac-As $) / A c] \times 100$

Where $A c=$ absorbance of control reaction, As = absorbance of the sample.

\subsection{ABTS decolorization assay}

The ABTS + + radical cation decolorization assay was performed spectrophotometric method. The ABTS+ scavenging activity was calculated previously described by Jakovljević (Jakovljević VD et al., 2016). Briefly, ABTS stock solution (7 mM) with $2.45 \mathrm{mM}$ potassium persulfate. The mixture was incubated in dark condition at room temperature for $16 \mathrm{hrs}$. Under this condition, ABTS+ could be stable in this form for 2 days. The ABTS+ solution was diluted double distilled water to obtain an absorbance of $0.70 \pm 0.02$ at $734 \mathrm{~nm}$. Aliquots of $30 \mu \mathrm{L}$ of the extract different concentrations then added to $2.7 \mathrm{~mL}$ diluted ABTS + + solution, and mixture was incubated at room temperature for $30 \mathrm{~min}$. Absorbance was recorded at $734 \mathrm{~nm}$. AA, was used as standards. The percentage of inhibition was calculated using foloowing formula:

\section{\%inhibition $=[($ Ac-As $) / A c] \times 100$}

Where $A c=$ absorbance of control reaction, As = absorbance of the sample.

\subsection{Ferric ReducingAntioxidant Power Assay (FRAP)}

The capability of the extract to reduce ferric ion $(\mathrm{Fe} 3+)$ to ferrous ion $(\mathrm{Fe} 2+)$ was determined using previous method I. F. F. Benzie and J. J. Strain (I. F. F. Benzie and J. J. Strain 1996) with some modification. Briefly, $300 \mathrm{mM}$ acetate buffer $(\mathrm{pH}$ 3.6) was mixed with $10 \mathrm{mM}$ TPTZ and $20 \mathrm{mM} \mathrm{FeCl} 3$ -6H2O with 10:1:1 ratio. FRAP reagent was used as a blank and measured at $593 \mathrm{~nm} .100 \mu \mathrm{L}$ extract and $300 \mu \mathrm{L}$ distilled water were added to the blank. Took second reading after 4 minutes. Fe(II) was prepared as a standard with numerous concentrations from 0 to $100 \mu \mathrm{g} / \mathrm{mL}$. The results were shown as the concentration of antioxidant having a ferric reducing ability in 1 gram of sample $(\mathrm{mM} / \mathrm{g})$. 


\section{Results and Discussion}

\subsection{Total Phenolic, Flavonoid and Anthocyanin Contents}

Anthocyanins, Phenolics and Flavonoids are the phytochemicals that usually presented in berries and known to have antioxidant, anticancer, antiinflammatory, antimutagenic, antihypertension and antineurodegenerative. Naturally, these phytochemicals are very essential components for physiological functions of plants such as pathogens , for pollination, herbivore and protection against UV light ${ }^{[9]}$. Therefore, the amount of the total phenolic, anthocyanin and flavonoid content Rubus idaeus was determined. The results were presented in Table 1. The raspberry fruit extract phenol content $37.19 \pm 0.39 \mathrm{mg} \mathrm{GAE} / \mathrm{g}$, flavonoid content 5.32 \pm 0.13 $\mathrm{mg}$ RU/g were recorded. Total anthocyanin contents $32.21 \pm 0.35 \mathrm{mg} \mathrm{c}-3-\mathrm{gE} / \mathrm{g}$ was displayed by Rubus idaeus fruit.or above the table as specified using font size of 9 or 10 .

Table 1. Anthocynin, Phenol and Flavonoid Content of Rubus

\begin{tabular}{|c|c|c|c|}
\hline & $\begin{array}{c}\text { TPC } \\
(\mathbf{m g ~ G A} / \mathbf{g})\end{array}$ & $\begin{array}{c}\text { TAC } \\
(\mathbf{c - 3}-\mathbf{g E}) / \mathbf{g} \\
\mathbf{D S}\end{array}$ & $\begin{array}{c}\text { TFC } \\
(\mathbf{m g ~ R U} / \mathbf{g})\end{array}$ \\
\hline $\begin{array}{c}\text { Methanol } \\
\text { Extract }\end{array}$ & $37.19 \pm 0.39$ & $32.21 \pm 0.35$ & $5.32 \pm 0.13$ \\
\hline
\end{tabular}

\subsection{DPPH, FRAP and ABTS Assays}

The antioxidant capacities of Rubus idaeus was measured using three dissimilar in vitro antioxidant assays. In DPPH assay, DPPH solution's purple color changed into yellow color due to presence of antioxidant compound.The antioxidant capacity of extract on DPPH free radical was presence of hydrogen-donating ability. The $\mathrm{IC}_{50}$ value $39.00 \pm 1.32$ was measured of raspberry fruit.

FRAP method used to determine the antioxidant capacity. In this method, ferric ion is reduced to ferrous ion at low $\mathrm{pH}$, colored ferrous tripyridyltriazine complex formed .The reducing ability of Rubus idaeus fruit $52.03 \pm 4.65 \mathrm{mM} \mathrm{Fe} 2+/ \mathrm{g}$ was recorded.

ABTS decolorization assay is similar to DPPH assay, which is the scavenging activity of the free radicals. However, the ABTS salt generated by chemical and enzymatic reaction first. The Rubus idaeus fruit extract shown lower scavenging effects against ABTS radicals. The raspberry fruit was recorded $0.85 \pm 0.02 \mathrm{mg} \mathrm{AEAC} / \mathrm{g}$ ABTS scavenging activity. FRAP, ABTS and DPPH assays results were presented in table 2 .

Table 2. DPPH, ABTS and FRAP assays of Rubus idaeus

\begin{tabular}{|c|c|c|c|}
\hline & DPPH & ABTS & FRAP \\
\hline $\begin{array}{c}\text { Methanol } \\
\text { Extract }\end{array}$ & $39.00 \pm 1.32$ & $0.85 \pm 0.02$ & $52.03 \pm 4.65$ \\
\hline
\end{tabular}

DPPH free radical scavenging activity represented by $\mathrm{IC}_{50}$ was expressed as $\mu \mathrm{g} / \mathrm{mL}$.

ABTS free radical scavenging activity was expressed as $\mathrm{mg}$ ascorbic acid equivalent antioxidant capacity (AEAC) in $1 \mathrm{~g}$ of dry sample.

FRAP was expressed as $\mathrm{mM}$ ferric reduction to ferrous in $1 \mathrm{~g}$ of dry sample.

\section{Conclusions}

Raspberries are a excellent natural source of antioxidant compounds such as tannins. Rasberry rising consumer interest to antioxidant phenotypes in a healthy diet. The antioxidant phytochemicals, several anthocyanins and ascorbic acid are present in rasberry. Our results specify that inconsistency in phytochemicals content of Rubus idaeus investigated which may be due to the environmental and genetic factors. Methanol extract of $R$. idaeus fruit showed a major quantity of phytochemicals, which gives to antioxidant, antibacterial, and antiacetylcholinesterase activities. Consumption of Rubus idaeus fruit in diet can offer healthy benefit.

\section{Reference}

1. A. Jim'enez-Arellanes, J. Cornejo-Garrido, G. Rojas-Bribiesca et al., "Microbiological and pharmacological evaluation of the micropropagated Rubus liebmannii medicinal plant," Evidence- Based Complementary and Alternative Medicine, vol. 2012, 2012, Article ID 503031, 7 pages,.

2. Borges, G., Degeneve, A., Mullen, W., \& Crozier, A.. Identification of flavonoid and phenolic antioxidants in black currants, blueberries, raspberries, red currants and cranberries. Journal of Agricultural and Food Chemistry, 58, (2010), 3901 - 3909. doi:10.1021/jf902263n

3. Brighente IMC, Dias M, Verdi LG, Pizzolatti MG. Antioxidant activity and total phenolic content of some Brazilian species. Pharmaceutical Biology 45(2),(2007):156-161.

4. C. S. Bowen-Forbes, Y. Zhang, and M. G. Nair, "Anthocyanin content, antioxidant, antiinflammatory and anticancer properties of blackberry and raspberry fruits," Journal of Food Composition and Analysis, vol. 23, no. 6, 2010, pp. 554-560,.

5. Heinonen, I., A. Meyer, and E. Frankel.. Antioxidant activity of berry phenolics on human low-density lipoprotein and liposome oxidation. J. Agr. Food Chem. 46: 1998, 4107-4112.

6. H. Jung, H. J. Lee, H. Cho, K. Lee, H.-K. Kwak, and K. T. Hwang, "Anthocyanins in Rubus fruits and antioxidant and anti-inflammatory activities in RAW 264.7 cells," Food Science and 
Biotechnology, vol. 24, no. 5, 2015, pp. 18791886.

7. I. F. F. Benzie and J. J. Strain, "The ferric reducing ability of plasma (FRAP) as a measure of ' antioxidant power' : the FRAP assay," Analytical Biochemistry, vol. 239, no. 1, 1996, pp. 70-76,

8. Jakovljević VD, Milićević JM, Delić GT, Vrvić MM. Antioxidant activity of Ruscus species from Serbia: Potential new sources of natural antioxidants. Hemijska Industrija 70(1), (2016):99-106.

9. J. J. Dragǐsic Maksimovic, J. M. Milivojevi'c, M. M. Poledica, M. D. Nikoli'c, and V. M. Maksimovi'c, "Profiling antioxidant activity of two primocane fruiting red raspberry cultivars (Autumn bliss and Polka)," Journal of Food Composition and Analysis, vol. 31, no. 2, 2013, pp. 173-179,.

10. Landele, J.M. (2011). Ellagitannins, ellagicacid and their derived metabolites: A review about source, metabolism, functions and health. Food Research International, 44, 2011, 1150-1160. doi: 10.1016/ j.foodres.2011.04.027,

11. M. M. Giusti and R. E. Wrolstad, “ Characterization and measurement of anthocyanins byUV-Visible spectroscopy, " Current Protocols in Food Analytical Chemistry, unit F1.2, 2001, 13 pages,.

12. Rao, A.V., \& Snyder, D.M. (2010). Raspberries and human health: a review. Journal of Agricultural and Food Chemistry, 58, 38713883. doi:10.1021/jf903484g
13. USDA. Scientific report of the 2015 Dietary Guidelines Advisory Committee. Washington (DC): USDA; 2015. [cited 2015 Jan 2]. Available from:

http://www.health.gov/dietaryguidelines/2015scientificreport/ PDFs/Scientific-Report-of-the2015-Dietary-Guidelines-AdvisoryCommittee.pdf.

14. USDA. National nutrient database for standard reference service release 27 and the flavonoid content of selected foods release 3.1 [Internet]. Washington (DC): USDA Agricultural Research Services [cited 2015 Apr 10]. Available respectively from: http://ndb.nal. usda.gov/ndb/search/list and http://www.ars.usda.gov/News/docs. htm?docid $=6231$.

15. Zafra-Stone, S., T. Yasmin, M. Bagchi, A. Chatterjee, J. Vinson, and D. Bagchi.. Berry anthocyanins as novel antioxidants in human health and disease prevention. Mol. Nutr. Food Res. 51: 2007, 675-683.

16. Wootton-Beard PC, Moran A, Ryan L. Stability of the totalantioxidant capacity and total polyphenol content of 23 commerciallyavailable vegetable juices before and after in vitro digestion measured byFRAP, DPPH, ABTS and Folin-Ciocalteu methods. Food Research International 44(1): (2011), 217-224.

17. Takao T, Kitatani F, Watanabe N, Yagi A, Sakata K. A simple screening method for antioxidants and isolation of several antioxidants produced by marine bacteria from fish and shellfish. Bioscience, Biotechnology and Biochemistry 58(10): (1994), 1780-1783. 